\title{
Literacy, Ethnicity and Style
}

\author{
Maria Sílvia Cintra \\ Department of Modern Languages, Universidade Federal de São Carlos, São Carlos, Brazil \\ Email: msilviam@ufscar.br
}

Received June $26^{\text {th }}$, 2013; revised July $23^{\text {rd }}$, 2013; accepted August $24^{\text {th }}$, 2013

\begin{abstract}
Copyright $@ 2013$ Maria Sílvia Cintra. This is an open access article distributed under the Creative Commons Attribution License, which permits unrestricted use, distribution, and reproduction in any medium, provided the original work is properly cited.
\end{abstract}

\begin{abstract}
I present the result of a two-year research project developed at the "Instituto de Estudos de Linguagem" (IEL/Unicamp, Brazil) and also of action research I have been organizing since 2006 when I started to work as a professor at the "Universidade Federal de São Carlos", in Brazil. Relying on recent developments in New Literacy Studies, I explore the concept of the continuum illiterate-literate and argue that it implies elements of transformation, as well as conservation. I also argue that three intersecting continua must be considered together: the continua oral-written, rural-urban and restricted-full literacy, always taking into consideration ethnicity as a variable (Cohen, 1974). Drawing on ethnographic fieldwork in Brazil, I show how elements of restricted literacy (Goody, 1968) are presented on the threshold of the twenty first century; how they entertain relation with the rural to urban migration and with a marked contrast between different ethnicities; and in what sense this fact may be visible in the everyday use of language and in the style inherent in it.
\end{abstract}

Keywords: Urban Ethnicity; Arena of Conflict; Indigenous

\section{Introduction}

My initial project was entitled "From Speech Acts to Literate Practices" and I intended to understand the interface between the written and the oral on the basis of the conceptions developed by Voloshinov (1973) and by Bakhtin $(1981,1986)$ concerning speech acts and discourse genres. The fact is that I was not yet aware of the reality that oral and written languages consist of overlapping realities, which are impossible to understand as separate unities. In this sense, I still defended the idea of a continuum of discourse genres which would range from oral to written language or from informal to formal registers in a somewhat separate fashion. That is the way I imagined a transition from speech acts to literate practices when I first started to visit a community in the outskirts of São Carlos, a city of about 220,000 inhabitants in the southeast of Brazil, 95\% of whom reside in the city and only $5 \%$ in the rural area.

As I began to collect field data, I continued to study, together with the group of students I supervised, Bakhtin's and Voloshinov's theory, and to improve my understanding of the sociohistorical approach from Fairclough's tridimensional proposal (1992, 1995, 2003). Some important insights were given later on by Certeau (1980), Goffman (1959) and Cohen (1974) as I gradually enlarged my understanding of language in general and started to envisage it more and more as a part of culture and ethics.

\section{Method}

The methodology used for action research was adopted once I not only intended to collect data regarding literacy, but I was also interested in education and in transformation (Freire, 1972; Cameron, 1992; Thiollent, 1986).
In his "Pedagogy of the oppressed”, Freire (1972) proposes a method of research which is intimately related with education, inasmuch as the limit between the research itself and education is very subtle and most often we have an overlap between both processes. In principle, it is argued that the educator should first visit the community where they intend to develop an educational practice in order to raise awareness of the "generating themes" they will work with. However, as the process of research is supposed to be carried out in a dialogical fashion, and as the researcher is expected to be attentive to the community's problems and tensions, there is not only the movement of grasping the questions present in such a reality; problem-solving is also very intensively present with reference to the necessity the researcher feels to discuss the questions that emerge in order to find the best solutions together with the subjects of the research. As a result, there is a rich blend of research and education.

Cameron (1992), on the other hand, defends empowering research as a form of academic research that endeavors to respect the subjects' agenda, i.e., the emphasis is not centered on the researcher's priorities, but rather on the problems and tensions present in a certain community and on the ethic compromise the researcher feels concerning questions of marginality, hegemony, contra-hegemonic forces and empowerment.

Thiollent (1986) defines action research as a kind of social research of empirical basis which is conceived and carried out in close relation with an action and with the solution of a collective problem. In this case, the researchers and the subjects of research are involved in a cooperative and participative fashion. In the case I will discuss, there was a constant movement from theory to practice, which is also a characteristic of action research. As a consequence, the results I will present will reveal 
this constant relation. I will show theoretical data together with certain vivid examples that illuminate these data and make it possible to think about theory in a more in-depth and detailed fashion. Taking this into account, I strongly believe in the importance of doing ethnographic research as a way of constantly checking the theory we deal with and building new conceptualizations.

The initial research project I mentioned was based on the assumption that we still lack better knowledge of the heterogeneous reality of language as it is practiced by individuals who are in the initial phase of accessing written language in the standards of urban environments. I had chosen a group of adults considered illiterate or semi-literate; I expected, however, that the results of my research could contribute to the reflection about literacy in general, and to the understanding of the continuum illiterate-literate in particular. I also believed that some aspects of the use of adult language could bring a better understanding about children and teenagers' use of language and about their difficulties with school literate practices. Only later on, when developing another research project related to indigenous people in Brazil, I could understand better that probably part of the inhabitants of suburbs similar to the one I refer to are indigenous, though they do not identify as such.

It is worth mentioning here that according to a recent government survey from the IBGE (Brazilian Institute of Geography and Statistics), 7.4 million young Brazilians aged between eighteen and twenty nine (from a number of 34 million urban youngsters making a total of $21.7 \%$ ) have had only one to seven years of school study-which means abandoning school before completing the basic level of nine years. Moreover, 813.2 thousand-almost one million young people-are considered illiterate. Alagoas, a state in the northeast of Brazil, leads the ranking with $46 \%$ of youngsters in either case. On the other hand, São Paulo state, which is located in the southeast region and is the richest and most developed Brazilian state, has 15\% of youngsters who are subject to what one may consider "restricted literacy" (Goody, 1968) as far as one takes into consideration literacy not as a multiple phenomenon, but rather as a certain standard socially chosen that must be attained for one to be considered literate (Street, 1993).

It is also worth taking into account the fact that as a result of ethnicity, i.e., of the form of interaction among cultural groups operating inside common social contexts (Cohen, 2004: p. xi), self-identification concerning ethnic issues is problematic in Brazil. That is why the last IBGE survey in 2010 revealed only $0.4 \%$ of indigenous people in our country.

I coordinated biweekly meetings at a cooperative of manual workers in the outskirts of São Carlos, an average-sized city in the southeast of Brazil, with the double objective of teaching language and collecting research data. At the same time, I gave a course at the university and some of my students used to participate in the Saturday meetings with me. There were ten students who alternated in going along with me, so that two or three academic researchers always went. In the community, there used to be about three or six people. We insisted on trying to convince more adults to participate in the meetings, but with time we began to understand that though limited in number, the group could in a certain way serve as literacy agents in their everyday contact with the rest of the community. The cooperative consisted of about 260 manual workers, and most of them came from a recent process of urbanization.

We used different strategies for collecting data, including semi-structured interviews, filming, tape-recording and notetaking. Preference was given to semi-structured interviews which were considered more appropriate to action research in the sense that they imply more freedom and flexibility. Every meeting was filmed and the group of researchers alternated in taking notes and engaging in dialogues with the subjects. Another group of researchers transcribed the recordings.

\section{Results}

The partial results I will present here involve, on one hand, discussion of the theory I explored while developing action research; on the other hand, they involve data collected in fieldwork.

\section{From Speech Acts to Literate Practices}

In “The Problem of Speech Genres”, Bakhtin (1986) proposes the difference existing between primary and secondary or complex genres. It is worth paying attention to the assumption detached by the Russian philosopher that secondary genres absorb and transform the primary genres previously constituted. Spontaneous verbal communication and informal letters are given as examples of texts pertaining to primary genres, whereas romance, theater and scientific discourse would represent secondary genres. The former are defined on the basis of their spontaneous constitution and of a direct relation with immediate reality, and it is said that the latter are mainly written and entertain rapport with a world represented by language, rather than with the surrounding world. It is also worth remembering that, as a philosopher, Bakhtin was mostly interested in a phylogenetic approach and not so much in an ontogenetic one.

It is certainly possible to think of language as ranging smoothly from informal to formal registers. However, when we assume Bakhtin's theory as pertaining to a socio-historical approach (together with Vygotsky's, 1985) it is necessary to consider that the transition from one to another phase implies rupture as well as conservation. Furthermore, it also implies envisaging language as an inherent part of social relations and culture. Taking this into account, I gradually began to understand that it would be misleading to think of Bakhtin's discourse genres without taking into consideration, simultaneously, Voloshinov's theorization on social psychology and on ideology. I also understood that, in a certain sense, primary genres pertain to everyday life ideology, whereas secondary genres are part of the ideology of super-structures, but this assumption may also be misleading when lacking a dialectic view.

Inspired by Freire's previous work with adult learners, we called our biweekly meetings "Cultural Sessions". At each session, I took a different text, always pertaining to a secondary genre: a short film, a poem, a map, an interview. Some students suggested that we should take three films together with a short explanation about each one in order to encourage the community participants to choose which they would prefer to see and therefore involve them more. They suggested the films "Modern times", "Thank you for smoking” and a third one, a short Brazilian film entitled "Island of Flowers" ("Ilha das Flores") about nature preservation. The students understood that it was important to take films which involved some sort of social criticism; I defended that it was not only the content that was at stake, but the structure of each genre, in the sense that the inhabitants of that community were not used to the kind of irony 
and simulation which certain films explore. Nevertheless, we took the three films and, after a short talk, the participants chose the film “Thank you for smoking”. At a certain point of the session, I noticed that the community participants seemed somewhat bored and indifferent, so I decided to start making some intermediary comments in order to provoke their involvement. As a matter of fact, it was necessary to make some metalinguistic interference and some purposeful joining between the oral language of everyday life and the film so that such a text could be fully understood by those adult learners.

It was plainly visible that a film, as a text pertaining to secondary genres, involves elements of dialogue typical of primary genres. From an ontogenetic point of view, however, we did not feel that this explanation was reasonable to make us understand why there still remains some difficulty for adults considered semi-literate to read and understand such texts. At first sight, it seemed to us that exactly because of the multimodality present in them, they would be easier to understand for the kind of students we dealt with. Practice, however, denied our assumptions and brought to light the fact that even humor was not as accessible as we imagined beforehand - at least a certain kind of intellectual or ironic humor.

In the course of the process involving several "Cultural Sessions”, I gradually developed the understanding of two fundamental questions. First, the evidence related to the fact that primary genres persist in secondary genres only in a simulated form - and not in a more direct or quite accessible fashion. In other words: accompanying the dialogues existing in films similar to the one we had presented apparently requires a kind of experience different from the most simple one people deal with in everyday life face to face communication. A certain kind of dialogue explored in films as well as in advertisements, in cartoons or in comic strips is not as straightforward as it may seem to people who have benefited from the availability and the access to certain urban literacy practices. Second, the evidence involving the fact that the simulation present in language must be accompanied by simulating new roles in social inter-relation. If it was true-as I believed - that the continuum illiterateliterate should be seen together with the continuum restrictedfull literacy, more and more I was convinced that language certainly has to be seen as part of social interplay, but not in a harmonious way, and rather in the sense of conflicting social struggle for hegemony and for full citizen participation, in the sense Cohen (1974: p. xiii) deals with ethnicity as comprehending "the potency of the normative symbols the individual manipulates in his struggle for power".

Taking this into account, restricted literacy as seen inside an ideological model must mean a restricted form of participation and of access to different opportunities in society in general. Language, thus, is not generally accessible unless it accompanies the playing and the simulation implicit in the roles we engage in as we take part in literacy practices inherent to determined social groups. In this sense, it may seem available without being plainly accessible (Kalman, 2004)—and accessibility has to do with real pertaining to social groups and sharing power.

Later on, since 2008, when indigenous youngsters coming from different parts of Brazil started participating in different courses of our university, all the issues discussed here acquired a clearer outline. Certainly the transition from a literacy practice to another one could not and would not be smooth. Academic structure was not permeable; prejudice would be present and conflict as well. One indigenous undergraduate student would say to me: "The professor explains, but I cannot understand what he says". He was not referring to a difference between Portuguese and an indigenous language once most indigenous youngsters today in Brazil speak Portuguese as their first language; he was referring to a difference present within a same language, i.e., in the sense he considers academic language as if it were a technical language not as accessible as one could imagine at first sight.

\section{Some Considerations on Restricted Literacy}

Goody (1968) referred to West Africa and India as cases of restricted literacy. On the other hand, Gumperz (1986) referred to minority groups situated in the urban outskirts or in rural areas in the United States, and pointed out the apparent difficulty for learning in these communities. I argue that in any of these cases, it is the same reality that may be envisaged by means of the continuum restricted-full literacy. In Brazil, as I understand it, we have a case of restricted literacy similar, up to a certain degree, to the Indian one. There are characteristics proper to restricted literacy (Cf. Goody, 1986), such as: appeal to magic-religious conceptions; resource to formulaic style; tendency to secrecy; persistence of oral modes of instruction; emphasis on rote learning (even at university); oral residues in a literate culture; tendency towards preciosity. At first sight, however, there seems not to be, in this case, a strong association between writing and religion. It is possible, anyway, to recognize the intersection of three continua: the continuum oral-written, the continuum rural-urban and the continuum restricted-full literacy, which we can say intersect. Restricted-full literacy deals with questions related to power, to secrecy, to cipher and, to initiation.

Without defending the autonomous consequences of literacy but, rather, understanding literacy from a sociological approach (Gee, 1990; Street, 1993; Barton \& Hamilton, 1998), I started to consider some data related to the socio-economic structure of Brazilian society that might explain why, in a twenty first century global society, in an emergent country, there are still traits characteristic of restricted literacy. According to a socio-historical and dialectic approach, however, the concept of "restricted literacy" must refer to a broader social reality rather than to the Subjects themselves whose level of literacy would be considered restricted: it refers to a social condition in which multiple literacies are not recognized as legitimate and a sacred status is attributed only to one of them.

Concerning the appeal to magic-religious conceptions, a fact that called my attention and that occurs with a certain frequency in adult classes was when Iraci (a fictitious name) declared "I pray that Jesus may open my head so that I can read”. At first sight, it seemed only an emotional expression, but as I met other people from a rural background who made similar statements, I started to suspect that they represented a broader reality. Many of the women have their first contact with literate events when going to church. They cannot read, but they are literate in the sense that they take part in events centered on literacy (Cf. Heath, 1983). As defended by Kalman (2004), we can say that they have contact with literacy, but not real access to it.

Other characteristics of restricted literacy-resource to formulaic style; tendency to secrecy; tendency towards preciosity -appear strictly related to the same question when we observe 
the behavior of those Subjects considered illiterate for whom literacy seems to be involved in an inaccessible aureole; on the other hand, I was shocked when, paradoxically, Jessica (another fictitious name), a postgraduate student who belonged to our research group, said: "Here at the university, most teachers seem to hide their knowledge”. Again, it could be seen just as a common complaint of students, but as I had been aware of these questions related to restricted literacy and secrecy, I began to conceive the idea of a continuum ranging from restricted to full literacy, which is more visible in the case of illiterate people who get in contact with literacy, but which would also exist in other situations and even at a university level. The two other characteristics which Goody pointed out-persistence of oral modes of instruction and emphasis on rote learning - are certainly present at lower levels-primary and high schools-but we can say they still persist at university when we consider that an oral mode of instruction does not only imply the behavior of teachers and students in the classroom, but, rather, the way written culture is still frequently regarded inside an untouchable bell jar, particularly in what concerns western European or American literate culture. As I understand it, this fact is partly a consequence of our belonging to a third-world country whose academic culture is mainly imported from first-world nations and often enough arrives in our country not as a result of autonomous field research, but rather as ideology in the sense constructed by Foucault (2002).

\section{The Idea of Assimilation: Ideology and Hegemony}

When taking into account the concepts of ideology and hegemony (Fairclough, 1992, 1995, 2003), as well as the concept of semiosphere (Lotman, 2005), I could envisage discourse genres in a more complex way. I gradually understood that genres assimilate characteristics previously existing (in the sense of the assimilation of primary genres existing in secondary genres) and that they reveal these characteristics because they are crossed by vectors of ideology and hegemony which, in principle, belong to the social dimension. It is interesting to point out that for Voloshinov (1973), ideology and power are constantly crossing social relations, which is different from the orthodox Marxist standpoint concerning infra-structure and super-structure relations. Considering this, if it is true that secondary genres assimilate and absorb all primary genres previously constituted (Bakhtin, 1986), this is only possible because certain elements proper of power and ideology persist in social relations in general exerting influence on language and on the style each Subject chooses in order to play their role inside such an arena.

Amanda (a fictitious name) was a very active member of the cooperative of cleaners in Jardim Gonzaga-the neighborhood in the outskirts of São Carlos where I developed my field research. She lived alone with her two children and showed much interest when coming to our meetings. She used to say that she did not like to engage in much conversation with her neighbors, that she had her private life and was not fond of much contact with others. With time, however, we understood that, paradoxically, she was a supportive woman: her eyes lit up whenever she mentioned her plans either concerning her family (brothers she had left far away in the northeast of Brazil and wanted to help) or the neighborhood (one of her dreams was about setting up a kindergarten for the children to stay in while their parents studied).

One Saturday afternoon, Amanda stated: “I don’t like to talk, because my speech is full of mistakes. People listen and notice that I say several words wrongly. I am ashamed, so I prefer to be silent”. It is worthwhile observing that Amanda could not feel strong enough to make use of symbols belonging to her community, i.e., of the style and of the identity pertaining to her community, an indigenous community of the state of Parana, in the South of Brazil. Stigma (Goffman, 1963) was present in such a way that she would rather be silent.

I listened to her and could hear no mistakes. I commented to her that her speech was absolutely right, but she said she still wanted to learn the "right" way, only then she would be satisfied. What she understood as the "right" way involves the accent proper to southeastern speakers and, sure enough, a certain way she recognizes in the speech of Brazilians who entertain a more sophisticated literate condition. Or, in other words, the form of speech proper to citizens who are most involved in urban complex genres of discourse.

\section{Ethos and Ethics}

Brazil is still considerably shaped by traits belonging to rural communities and culture ${ }^{1}$. Since the beginning of the twentieth century, there has been a permanent movement characterized by rural exodus and by the continuous insertion of illiterate people into the literate universe of different cities. This fact has meant complex consequences for communication as different ethnicities are involved implying different ethé which are often ignored when education is centered on certain matters considered of universal reach, and also when developing ethnographic and action research. There are some different traits pertaining to each ethnicity-as one takes into account rural illiterate ethnicity and urban literate ethnicity, as well as the phenomenon of ethnicity as "a matter of degree" (Cohen, 1974: p. xiii)—which point to a link between ethics, on one hand, and ethnicity, on the other. I think such an approach can contribute to a better understanding of literacy and of the continuum illiterate-literate and that this understanding is fundamental for education as a whole, and not only for beginning literacy instruction. Moreover, it can provide a better understanding of the communication between academic researchers and the subjects of their research, as in the case of an experiment developed by another group of professors and academic researchers of a Brazilian university who wanted to contribute to building cheap and comfortable houses for rural inhabitants, as well as developing popular co-operativism, but have had difficulties implementing their proposal ${ }^{2}$.

I had been reading about the concepts of ethos and ethics when I started visiting the community I have been mentioning. Later on, I also could understand better that each semiosphere comprehends their ethos (Lotman, 2005). In principle, I understood ethos as a part of language itself, inasmuch as language and identity are intimately linked. As I observed conversation

\footnotetext{
${ }^{1}$ In the city of São Carlos where my research was developed, and which is part of the richest region of our country, only $5 \%$ of the population resides in the rural area, contrasting, for instance, with Cabeceiras, a town of about 8300 inhabitants in the northeast of Brazil, where more than $85 \%$ of the population still live in a rural area.

${ }^{2}$ I took part in an interdisciplinary research team which includes professors, undergraduate and postgraduate students from different areas: engineering, architecture, health and social sciences. The experience implying the construction of houses was developed in a sector related to mine. It was not part of the literacy project, but my group of students and I was able to follow the development of their action and take notes related to our interests.
} 
engaged between a professor and the president of a popular cleaning cooperative, I progressively began to see that ethos is related to questions of ideology and hegemony as well, in the sense that once it represents a habitus, it is concerned with the culture and the ethics present in a certain community. The professor addressed the popular worker in what we can call a professoral ethos: he asked certain questions for which there was an expected answer, as if he were in fact in a classroom environment. In this case, it is interesting to think of what Fairclough (1992) calls hybridism. It is worth mentioning the fact that not only genres undergo hybridization: there are social spheres that intersect. It is as if the professor had forgotten that he was engaged in the genre of an informal conversation (pertaining to primary genres) and started behaving in tune with a classroom ethos, i.e., in accord with secondary genres. As I will discuss below, this fact also has to do with the continuum restricted-full literacy, in the sense that, partially, we can say that the professor assumed a literate ethos whereas the cooperative worker played an oral role; on the other hand, it is possible to see, in such a behavior, a difficulty of communication proper to a place where a certain standard of literacy is still restricted to a few, whereas other multiple literacies are considered as nonlanguage (Lotman, 2005), i.e., people who are involved in such practices are considered as illiterate.

In fact, there seems to be an abyss between our literate ethics and logical thinking and the way some people considered illiterate think and behave. Furthermore, this transcends logic in the sense Luria (1979) brought to light: it has something to do with logic, but it also has to do with ethics and ethnicities. In this case, I concluded that the difference between oral and scriptural ethé might be at stake. Oral ethos implies reference to family and community bonds whereas the acknowledgement of rules present in broader social coexistence is typical of scriptural ethos. In either case, however, we have strict rules which are learnt implicitly or explicitly belonging to particular social groups. It is, therefore, impossible to think about different discourse genres belonging to different social practices and behaviors as smoothly ranging from one to another pattern. The transit from restricted to full literacy implies changing one's participation in a certain ethic in order to start one's familiarity with another one. Social roles, however, are not so smoothly or harmoniously interchangeable.

\section{Discussion: When Ethnicity Crosses Literacy: Style as a Result of Confrontation and Assimilation}

My previous discussion concerns the fact that it is not just genres that incorporate elements present in pre-existing realities; it is social reality that involves the coexistence of old and new elements, of archaic and modern social relations and ethé ${ }^{3}$.

Taking this into account, when rural adults considered illiterate start to have contact with urban literacy, it is not only the written language they have to dominate: there are different ethnicities in confrontation or, making use of the Bakhtinian conception, but also there is an arena of social struggle and conflict. There is a fight for hegemony, which does not only imply a struggle for participation in urban hegemonic literate alterity and ethos, but it also implies a confrontation and an attempt towards maintaining old structures with which one is most

${ }^{3}$ On the basis of Lotman's concept of semiosphere (Lotman, 2005) we can better understand the relation between ethos and ethnicities. concerned with. Again, we are before the intersection of the ethnicity variable across the illiterate-literate and rural-urban continua, which, in a certain sense, consist of the same continuum, as far as we take into consideration social reality as a whole and all the elements it is formed of ${ }^{4}$.

Post-modernity emphasizes diversity and, at this point of my conclusion, it is pertinent to raise the question: in what sense is it possible to coexist with diversity or to provide that different ethnicities coexist when we know that confrontation and a struggle for hegemony is involved? Or in other words: in what sense should different ethnicities coexist when they involve questions related to ideology and to power?

Many years ago, when I taught at a secondary school in a very poor neighborhood located on the seashore of a southeastern Brazilian town, I was explaining to my fourteen-year-old students socio-linguistic concepts related to variation and diversity. I said that there was a verbal form in Brazilian Portuguese which had more prestige ("eu pus") and another one which was also correct, but suffered stigmatization (“eu ponhei”). I explained that their use depended on social context and on the choice of different language styles, so that each of them could be adequate for a different situation, but neither could be considered incorrect. In a peculiar form, I was defending postmodern relativism and diversity. I said that "eu ponhei" could be used at home or in the neighborhood, together with friends or with their family; and that "eu pus" should be preferred in more formal contexts ${ }^{5}$.

A tall Afro-Brazilian student raised his hand and said: "I do not agree with this concept. Before, I used to say 'eu ponhei', but as soon as I knew this was a wrong verbal form, I did not want to pronounce it any longer.” The prejudice against the popular variety of Brazilian Portuguese is very deep-rooted, characterizing restricted literacy. Ideology and the struggle for hegemony are definitely presented in everyday relations and conversation, in the arena Bakhtin refers to, of dialectic and dialogical social confrontation and struggle. In this context, it becomes very difficult to defend the pacific co-existence of diverse registers, because one is not able to convince citizens on the basis of argumentation, when the very struggle for recognition in society depends on the domination of the language of the other and of his proper ethos and alterity.

Only later on, I would understand, together with Cohen (1974) and Cardoso de Oliveira (2006), ethnicity as a factor of style, i.e., as emergent socio-cultural phenomena implying confrontation among different ethnicities and generating style as a trait of identity. According to Cardoso de Oliveira, when considering Brazilian society, one must take into account the fact that one ethnicity enjoys hegemonic status within asymmetric relations including a variety of different ethnicities, i.e., there is a panorama in which different ethnic groups coexist in the same social and political space (or “arena”, using Bakhtin’s terms) dominated more intensively by one of them (Cardoso de Oliveira, 2006b: p. 178). Regarding the Afro-Brazilian student, I interpreted that he would prefer to play his role in the arena of conflict making use of hegemonic symbols, rather than the symbols present in his community as a kind of camouflage for his persona (Goffman, 1968).

\footnotetext{
${ }^{4} \mathrm{~A}$ discussion on the concept of ethnicity in its relation with literacy can be found in Martins (2011).

${ }^{5}$ The contrast between "he isn't" and "he ain't" may be given as an equivalent for this variation in Brazilian Portuguese. It should be mentioned that this is not a direct translation of "eu pus"/“eu ponhei”.
} 
The continuum restricted-full literacy as far as it also involves rural to urban migration points to the fact that history is at stake and that linguistic studies are part of a broader reality that calls for a socio-historical as well as for an anthropological approach. The defense of a pacific coexistence of the diverse may be possible in countries where a certain social equality is presented. In the case of Brazilian reality, however, we are in the middle of a historical transition from rural to urban life which involves the difficult conquest of a place of citizenship and of more thorough social participation. This reality implies, on one hand, the recognition and acknowledgement of diversity and alterity; on the other hand, however, it requires the very struggle for hegemony, which means the struggle to ensure a prominent place reserved for protagonist roles and not just for supporting or subservient ones.

\section{Acknowledgements}

I acknowledge Fapesp (04/15539-3) for supporting the initial two years of fieldwork, as well as Fapesp (09/13871-4 and $12 / 15852-0$ ) for supporting further research involving indigenous people.

\section{REFERENCES}

Bakhtin, M. (1981). The dialogical imagination. Austin, TX: University of Texas Press.

Bakhtin, M. (1986). The problem of speech genres. In Speech genres and other late essays (pp. 60-102). Austin: University of Texas Press.

Barton, D., \& Hamilton, M. (1998). Local literacies: Reading and writing in one community. London and New York: Routledge.

Bortoni-Ricardo, S. M. (1985). The urbanization of rural dialect speakers: A sociolinguistic study in Brazil. Cambridge: Cambridge University Press.

Cameron, D. et al. (1992). Researching language: Issues of power and method. London/New York: Routledge.

Cardoso de Oliveira, R. (2006). Etnicidade, eticidade e globalização. In O trabalho do antropólogo (pp. 169-188). São Paulo: Editora UNESP.

Certeau, M. (1980). L'invention du quotidien: Arts de faire. Paris: Gallimard.

Cohen, A. (1974). Two-dimensional man: An essay on the anthropol- ogy of power and symbolism in complex society. Berkeley: University of California Press.

Cohen, A. (1974). Urban ethnicity. London: Tavistock Publications Limited.

Cook-Gumperz, J. (2006). The social construction of literacy. Cambridge: Cambridge University Press.

http://dx.doi.org/10.1017/CBO9780511617454

Fairclough, N. (1992). Discourse and social change. Cambridge: Polity Press.

Fairclough, N. (1995). Critical discourse analysis. London: Longman.

Fairclough, N. (2003). Analysing discourse: Text analysis for social research. London: Routledge.

Foucault, M. (2002). The archaeology of knowledge. London: Routledge.

Freire, P. (1972). Pedagogy of the oppressed. London: Penguin.

Gee, J. P. (1990). Social linguistics and literacies: Ideology in discourses. London: The Falmer Press.

Goffman, E. (1959). The presentation of self in everyday life. New York: Doubleday Anchor.

Goffman, E. (1963). Stigma: Notes on the management of spoiled identity. Englewood Cliffs, NJ: Prentice-Hall.

Goody, J. (1968). Literacy in traditional societies. Cambridge: Cambridge University Press.

Heath, S. B. (1983). Ways with words: Language, life and work in communities and classrooms. Cambridge: Cambridge University Press.

Kalman, J. (2004). Saber lo que es la letra: Una experiencia de lectoescritura con mujeres de Mixquic. Mexico: Siglo Veintiuno.

Lotman, J. (2005). On the semiosphere. Sign Systems Studies, 33, 205-229.

Luria, A. R. (1979). The making of mind. Cambridge, MA and London: Harvard University Press.

Martins, M. S. C. (2007). Ethos, gêneros e questões identitárias. Revista Delta, 23, 27-43.

Martins, M. S. C. (2011). Letramento, etnicidade e diálogo intercultural. Revista Delta, 27, 77-98.

http://www.scielo.br/scielo.php?pid=S0102-44502011000100005\&sc ript=sci_arttext

Street, B. (1993). Cross-cultural approaches to literacy. Cambridge: Cambridge University Press.

Thiollent, M. (1986). Metodologia da pesquisa-ação. São Paulo: Cortez.

Voloshinov, V. I. (1973). Marxism and the philosophy of language. New York: Seminar Press.

Vygotsky, L. S. (1985). Thought and language. Cambridge, MA: The MIT Press. 